\title{
COMISSÃO DE LEGISLAÇÃO PARTICIPATIVA: A CONSTRUÇÃo DA DEMOCRACIA DELIBERACIONISTA*
}

\section{Nivaldo Adão Ferreira Júnior**}

Resumo: A Constituição de 1988 implementou o viés deliberacionista no modelo democrático brasileiro, o que possibilitou a criação da Comissão de Legislação Participativa na Câmara dos Deputados. No entanto, por ter sido concebida com o propósito primeiro de debelar a crise do Legislativo, e não de dar voz ao cidadão, a Comissão não tem realizado a contento nem uma das duas funções.

Palavras-chave: Câmara dos Deputados; Comissão de Legislação Participativa; Democracia; Democracia Deliberativa; Inclusão; Crise do Legislativo.

\begin{abstract}
The Brazilian Federal Constitution of 1988 adopted the theory of deliberative democracy parallel by the representative pattern. One of the consequences was the creation of a commission in the Brazilian Parliament that allows the civil society group participation in the initiative of the legislative process. However, due to be imagining as a solution to the Legislative Crisis but not to the lack of popular participation in the National Congress, the commission has not being solved neither the first nor the second problem.
\end{abstract}

Keywords: Chamber of representatives; Comissão de Legislação Participativa; Democracy; Inclusion; Legislative Crisis.

\footnotetext{
* Artigo produzido a partir de monografia apresentada ao Programa de Pós-Graduação do Centro de Formação, Treinamento e Aperfeiçoamento da Câmara dos Deputados, como trabalho final do Curso de Especialização em Processo Legislativo, sob orientação do Prof. Carlos Alberto Farias Nery.

** Advogado, Analista Legislativo da Câmara dos Deputados, especialista em Processo Legislativo pelo Programa de Pós-graduação do Centro de Formação, Treinamento e Aperfeiçoamento da Câmara dos Deputados nivaldo.ferreira@camara.gov.br
} 


\section{Introdução}

A democracia contemporânea é constantemente relacionada ao direito concedido ao cidadão de escolher seus representantes. Tanto é assim que o clímax democrático é identificado com os períodos de eleição, em que o calor das propagandas eleitorais, o momento do voto e a espera pelos resultados finais das urnas são chamados de "a grande festa da democracia". No entanto, o alcance do que se pretende com a inserção do princípio do Estado Democrático de Direito no Texto constitucional está bem além desse reducionismo.

Muito embora percebamos que o conceito de democracia (assim como o de Estado de Direito) tenha conteúdo histórico e que em cada época e lugar haja características peculiares a cada nação que o adota, não há como negar que, nos últimos anos, principalmente após as duas Grandes Guerras Mundiais, o modelo difundido majoritariamente no mundo ocidental traduz-se na adoção de uma democracia procedimentalista, elitista e minimalista. Procedimentalista porque reduz a democracia a um método para a eleição de representantes; elitista porque proporciona e privilegia a sucessão de grupos sociais minoritários e dominantes no exercício do poder; e minimalista por reduzir a participação popular ao ato de comparecer periodicamente às urnas e o ideal de alargamento da democracia ao alcance do sufrágio universal.

A base dessa teoria é a idealização de um governo democrático caracterizado pela participação popular mínima. Ainda que essa idéia contenha em si um paradoxo, muitos são os pensadores que vão se filiar a essa corrente e utilizá-la como sustentáculo para a construção de governos democráticos cada vez mais assemelhados a verdadeiras oligarquias. Entre esses estudiosos, destacam-se Joseph Schumpeter, que em Capitalismo, socialismo e democracia concebe o processo democrático meramente como um método de escolha de líderes políticos (1984, p. 352), e o filósofo italiano Noberto Bobbio, que assevera que "Joseph Schumpeter acertou em cheio quando sustentou que a característica de um governo democrático não é a ausência de elites mas a presença de muitas elites em concorrência entre si para a conquista do voto popular" (2004, p. 22). Para essa linha de pensamento, o conceito de democracia restringese a "um regime no qual todos os cidadãos adultos têm direitos políticos - onde existe, em poucas palavras, o sufrágio universal" (BOBBIO, 2004, p. 57).

No âmbito dessa corrente, vários argumentos são construídos para justificar o afastamento do cidadão dos procedimentos de discussão de políticas públicas e tomadas de decisões - como, por exemplo, a suposta falta de vocação da maioria dos cidadãos para as minúcias da política, o tamanho dos Estados, a complexidade das sociedades atuais -, de sorte a existir somente alguns poucos homens capazes de participar do governo: justamente os componentes da elite governante. Surge desse raciocínio a inevitabilidade das oligarquias dirigentes, e é por considerar as massas irracionais que os elitistas vão afirmar que "o preço que 
se deve pagar pelo empenho de poucos é freqüentemente a indiferença de muitos. Nada ameaça mais matar a democracia que o excesso de democracia"(BOBBIO, 2004, p. 39).

\section{Da crise da democracia representativa}

Essa democracia sem povo, calcada em bases meramente representativas e sem possibilidade de exercício direto do poder pelo seu detentor, está em crise, que se pode apreender por manifestações diversas. Em um primeiro momento, há a crítica à falta de legitimidade da democracia vigente, carência que se dá pelo afastamento da maioria da população das esferas de discussão e de tomada de decisões e pelo desrespeito, pelos políticos eleitos, às ideologias ou aos programas de governo (quando existentes) defendidos nas campanhas eleitorais. Esses fatos trazem como conseqüência o distanciamento entre a sociedade e o Congresso, fazendo do sistema uma democracia contemplativa (TRINDADE, 2005, p. 64).

Em um segundo momento, salienta-se a crise da democracia que se traduz na incapacidade de garantir a todos a igualdade de oportunidades no acesso a direitos básicos de cidadania. Essa desigualdade social, maior nos países periféricos, torna-se ameaça ao regime democrático, tanto no que diz respeito à sua efetividade, quanto à sua continuidade. A afirmação pode ser percebida nos resultados de pesquisa realizada na América Latina pelo Programa das Nações Unidas para o Desenvolvimento (PNUD), em que se verifica que 54,7\% da população latino-americana apoiariam um regime autoritário, se este fosse efetivo no combate à pobreza, na redução das desigualdades sociais e na garantia de resguardo de direitos civis básicos, enquanto não hesitariam em retirar o apoio a um governo democrático que não conseguisse atingir tal grau de efetividade (PNUD, 2004, p. 33).

Em um ainda terceiro enfoque, a crise da democracia é a crise das instituições políticas que, construídas para dar corpo ao Estado Democrático de Direito, não conseguem oferecer respostas aos anseios e necessidades da sociedade e de seus cidadãos. O descaso e a descrença da população em relação aos órgãos estatais, o absenteísmo eleitoral (inexistente no Brasil em termos significativos, quiçá pela obrigatoriedade do voto), a crítica aos três poderes estatais são os reflexos externos desse desequilíbrio, observando-se que, no Legislativo, justamente por ser o ramo do Poder que mais se identifica como representante legítimo do povo, essa cobrança popular retumba em tom mais elevado.

\section{A luta pela democratização da democracia na Constituição de 1988}

Com o propósito de mudar a realidade de uma democracia sem povo, e a de um Legislativo sem legitimidade, estudiosos contemporâneos pugnam por uma reforma política que substitua o paradigma procedimental por uma democracia com maciça participação popular. Para tanto, entendem como necessário alargar os espaços de discussão; possibilitar ao cidadão 
decidir diretamente ou, ao menos, opinar sobre assuntos atinentes às decisões fundamentais do Estado; e deferir aos governantes a oportunidade de, conhecendo melhor as reais demandas sociais, representar com representatividade ${ }^{1}$ os eleitores.

Uma das vozes exponenciais desse movimento é encontrada em Hannah Arendt (1981, p.111), para quem a criação de vários momentos de discussão e deliberação cidadã, por ela denominados de espaço da aparência, significa não só dar voz aos diversos grupos sociais, mas torná-los visíveis para o restante da sociedade, pois, por meio do discurso, os indivíduos deixam de ser coisas vivas, mas inanimadas, e assumem para si e para os outros uma aparência explícita e interativa, passando a existir socialmente. É o externar do discurso, portanto, que propicia aos demais atores sociais o conhecimento da realidade e das necessidades do grupo que se expressa.

A intenção dessa formulação deliberacionista é a de, ao gerar espaços públicos de participação, reconhecer nos excluídos a qualidade de cidadãos. Dessa sorte a voz dessa massa não beneficiada a contento no constitucionalismo liberal encontraria, por meio da interação com os centros decisórios, meios de realizar o controle social e de facilitar a implementação de políticas redistributivas.

A Constituição Federal de 1988, como resultado do processo de redemocratização surgido com o enfraquecimento da ditadura militar, esposou um regime de governo em que a interação da sociedade com o governo é tão importante quanto a representação política, filiando-se nitidamente à visão deliberacionista da democracia. Assim é que, no Texto, há a opção por um Estado democrático de direito que não mais admite que a participação popular seja considerada uma ameaça à democracia, ou mesmo ao instituto da representação. Ao contrário, é ela vista como componente intrínseco ao sistema estatal de tomada de decisões e, logicamente, como fator de legitimidade da representação.

A dar forma a esse propósito, a Carta dispõe em seu artigo primeiro que o poder emana do povo e será exercido indiretamente por meio de representantes eleitos ou diretamente por meio de várias ferramentas previstas constitucionalmente. Concretizando a prescrição inicial, o artigo 14 da Constituição traz algumas dessas formas de intervenção direta da sociedade nas decisões estatais - o plebiscito, o referendo e a iniciativa popular de lei - e, noutros momentos, torna a interação entre sociedade e Estado necessária à legalidade e à legitimidade da ação governamental, como ocorre, por exemplo, quando da exigência de gestão democrática como elemento obrigatório e de legitimidade dos sistemas da seguridade social e da saúde (cf. Constituição/1988, artigos 194, inc. VII e 198, inc. III).

Dessa forma, a Constituição da República institui o princípio da participação democrática, pois não só prevê um regime que combina a representação com elementos de

\footnotetext{
1 Representação com representatividade é conceito construído por Marion em Democracy e Inclusion. Oxford University Press, 2000, p. 121-53.
} 
democracia direta, em dispositivo topologicamente privilegiado (ainda em seu artigo primeiro), mas também faz irradiar, por todo o Texto, os efeitos desse regramento (NETO, 2005, p.21).

Por ser um princípio é que essa democracia participativa possibilita, ainda, a adoção de fórmulas outras que não as previstas constitucionalmente. Assim, encontram-se, nas legislações estaduais e municipais, por exemplo, a criação de conselhos comunitários e a aplicação de orçamento participativo. No entanto, a despeito de todas essas formas de interação com o Estado, a possibilidade de intervir no ordenamento jurídico é a que transfere maior parcela de poder à sociedade, e a que pode realmente propiciar uma transformação social.

Após quase vinte anos da promulgação da Constituição, contudo, não se pode negar que o braço representativo da democracia brasileira, até por tradição histórica, é o que se mostra hoje desenvolvido, o que nos coloca mais próximos do procedimentalismo schumpeteriano do que da vertente deliberacionista da democracia. Disso decorre que a crise da representação também atinge o Legislativo nacional, até porque a imensa desigualdade social, o crescimento econômico insuficiente e a incapacidade do Estado em garantir a muitos cidadãos os direitos e garantias mínimos para uma vida condizente com o sentido de humanidade ameaçam a estabilidade das instituições sociais e levam à contestação do modelo representativo dominante.

A face mais visível dessa realidade é externada pelos resultados das sucessivas pesquisas de opiniões realizadas no Brasil, em que se demonstra que as instituições políticas gozam de quase nenhuma credibilidade junto à sociedade. Em 1996, por exemplo, em dados estatísticos de pesquisa realizada pelo instituto chileno Latinobarómetro, observou-se que mais de $70 \%$ da população brasileira tinha pouca ou nenhuma confiança no Congresso Nacional ou na classe política (LOPES, 2004, p.18).

\section{A Comissão de Legislação Participativa}

Nesse contexto de plena revisão das teorias democráticas e de contestação da representação política, sendo o Congresso Nacional e seus membros o principal alvo da insatisfação popular, é que a Câmara dos Deputados criou, em 2001, a Comissão de Legislação Participativa (CLP). A Comissão veio como resposta e solução à imagem corrompida do Legislativo perante a sociedade e no expresso intuito de complementar a democracia representativa com um instrumento de participação que reduzisse a distância entre a sociedade e o Parlamento (CLP, 2001, p. 8). Como a crise da representação é igualmente sentida em todas as esferas de governo, várias outras casas legislativas logo se espelharam na iniciativa da Câmara dos Deputados e também criaram suas comissões participativas.

O principal objetivo que motivou a criação da CLP (e, imagina-se, a criação das demais comissões participativas), no entanto, não era o de dar voz aos grupos sociais excluídos das 
discussões políticas do Estado, nem o de dar concretude ao citado princípio constitucional da participação popular democrática, mas o de cuidar da representação política, ou mesmo o de fortalecê-la - embora afirmemos que os movimentos pela radicalização da democracia sejam suporte teórico para a criação do órgão. A percepção desse fato vem das palavras do então Presidente da Câmara dos Deputados, Dep. Aécio Neves, que afirma, no discurso de apresentação da CLP, que esta serve ao propósito de melhorar a imagem do Congresso, sem ter o condão de substituí-lo, dado que "um sistema que troque o voto popular e a representação política por outras formas de participação merecerá qualquer outro nome, não o de democracia" (CLP, 2001, p. 7). Nesse espaço de atuação, portanto, é que se permitiu a criação do órgão na função de

instrumento inovador com que a engenharia parlamentar busca responder a um dos mais preocupantes desafios da democracia contemporânea: como superar o perigoso abismo que vem sendo criado, nas sociedades de massa, entre os representantes e os representados (CLP, 2001, p. 7).

Em verdade, percebe-se que a criação de um espaço de discussão no Parlamento pelas próprias ferramentas institucionais deste Poder deixou transparecer a pressuposta pretensão de, deferindo poder à sociedade, preservar ou até potencializar os poderes dos representantes. A constatação, em certa dose, condiciona a atuação da CLP e deixa sobressair dúvida quanto à efetiva existência de uma mentalidade que acredite ser possível a realização do mandamento constitucional de deferimento aos cidadãos, aos grupos sociais, às minorias o acesso aos meios de informação e a possibilidade de voz e influência quanto aos programas e projetos governamentais.

A alimentar essa desconfiança, um olhar sobre os resultados alcançados nos mais de cinco anos de atuação deixa transparecer a baixa efetividade da Comissão, pois das 344 sugestões legislativas apresentadas ao órgão que buscavam a aprovação de uma norma para suprir demandas sociais, apenas uma logrou vencer as barreiras do processo legislativo e transformar-se em lei (CLP, 2006). Mesmo assim, para essa única lei de origem da CLP, o tempo de tramitação (mais de cinco anos) foi superior ao dobro da média do tempo necessário para aprovação de normas originadas de agentes legislativos diversos da CLP (CÂMARA, 2005, p. 106).

Esses dados tendem a demonstrar que a criação da Comissão participativa da Câmara teve muito mais apelo retórico do que prático e que pouca ou nenhuma importância é dada às demandas produzidas no espaço de discussão aberto aos grupos sociais dentro da Câmara, ou para ele direcionadas. Noutras palavras, a agenda de deliberação do Congresso não se sensibilizou com a produção da CLP. Os próprios parlamentares parecem não se interessar pelo órgão, pois é fato que em fins de abril de 2007 (dois meses após início dos trabalhos legislativos), treze, das trinta e seis vagas de membros suplentes e titulares existentes, ainda não 
haviam sido ocupadas (segundo informações dispostas no sítio eletrônico da Câmara dos Deputados). A exemplo dos deputados, também a sociedade não se deixou iludir por esse fogo fátuo, e o relatório de atividades da Comissão, editado em 2004, bem demonstra que parcas são as entidades que recorrem ao colegiado como solução a suas demandas legislativas (apenas 49, até aquele momento), demonstrando a baixa capilaridade do órgão junto à sociedade (CLP, 2004, p. 12).

O resultado desse desacerto não poderia ser outro que não o malogro no alcance do principal objetivo da criação da Comissão: estancar a crise da representação. A refletir esse fato estão os índices recentes de pesquisa realizada pelo Instituto DataFolha (2006), que indicam que apenas $12 \%$ da população brasileira consideram o desempenho dos congressistas brasileiros como sendo "ótimo" ou "bom" e quase $80 \%$ vêem na atuação parlamentar uma ação medíocre.

Nada obstante, não se pode olvidar do imenso potencial representado pela CLP no que tange ao aprimoramento da participação popular e democrática, pois o órgão traduz-se em acréscimo de liberdade ao cidadão: liberdade no sentido político de reconhecer quais são as questões prioritárias, do ponto de vista da sociedade, a serem discutidas e normatizadas pelo Congresso, o que torna a Comissão um caminho possível para se alterar a agenda de discussão do Legislativo. Além disso, mostra-se como resposta à carência de representatividade do Poder Legislativo quando se traduz na oportunidade dada ao cidadão, por meio das entidades sociais, de apresentar, sem intermediários, propostas legislativas. Essa ferramenta tem ainda o condão de educar o cidadão para ser capaz de pensar em suas prioridades e, a partir daí, tornar-se apto a melhor criticar seus representantes e deles cobrar a defesa do interesse coletivo, alinhando-se, nesse ponto, às correntes que postulam pela criação de instrumentos que promovam a educação cívica como forma de melhorar a participação popular qualitativamente.

Falta, contudo, a conscientização dos próprios parlamentares da necessidade de aprimoramento da Comissão de Legislação Participativa e do reconhecimento da importância dos embates travados em seu seio como expressão sincera dos anseios sociais. Quando os interesses pontuais ou as vontades do Executivo tiverem cedido espaço na pauta de discussão do Congresso às demandas legislativas oriundas da CLP, os eleitores enxergarão, na Comissão, o espaço público de discussão em que esta se constitui e, no Congresso e em seus membros, os reais representantes da sociedade.

\section{Referências}

ARENDT, Hanna. A condição human $a$. Trad. De Roberto Raposo, Rio: Forense e Salamandra; São Paulo: Ed. Universidade de São Paulo, 1981.

BENEVIDES, Maria Victoria, et. al. (org.). Reforma Política e cidadania. São Paulo: Fundação Perseu Abamo, 2005. 
BOBBIO, Noberto. O futuro da democracia; trad. de Marco Aurélio Nogueira. 9. ed. São Paulo: Paz e Terra, 2004.

BRASIL. Câmara dos Deputados. Anuário Estatístico do Processo Legislativo. Ano I (2005). - Brasília: Coordenação de Publicações, 2006 (série estatística legislativa).

BRASIL. Câmara dos Deputados. Comissão Permanente de Legislação Participativa. Cartilha. Brasília: Coordenação de Publicações, 2001.

BRASIL. Câmara dos Deputados. Comissão Permanente de Legislação Participativa. Nossa vivência e a difusão da idéia pelo País. Brasília, 2004. Disponível em: <http://www2.camara.gov.br/comissoes/clp/publicacao>. Acesso em: 26/06/2006.

BRASIL. Constituição (1988). Constituição da República Federativa do Brasil: texto consolidado até a Emenda Constitucional n. ${ }^{\circ}$ 52/2006 - Brasília: Senado Federal. Disponível em: <http://www.senado.gov.br/sf/legislacao/regsf/>. Acesso em: 3/5/2006.

DATAFOLHA - Pesquisa de opinião sobre aprovação do Congresso. Disponível em: <http://datafolha.folha.uol.com.br/po/aval_congresso_29052006.shtml>.

LOPES, Denise M. N, Nascimento. Para pensar a confiança e a cultura política na América Latina. In Opinião Pública, vol. 10, n.1. Campinas: FGV, 2004. Disponível em:<http://www.scielo.br/scielo.php?script=sci_arttext\&pid=S0104-

62762004000100007\#atab1a>. Acesso em: 12/07/2006.

NETO, José Duarte. A iniciativa popular na Constituição Federal. São Paulo: Revistas dos Tribunais, 2005.

PNUD - Programa das Nações Unidas para o Desenvolvimento. A democracia na América Latina, rumo a uma democracia de cidadãos e cidadãs(relatório). Trad. de Mônica Hirts. Santana do Parnaíba, SP: LM\&X, 2004.

SCHUMPETER, Joseph A. Capitalismo, socialismo e democracia. Trad. De Sergio Góes de Paula, int. de Tom Bottomore. Rio: Zahar, 1984.

YOUNG, Iris Marion. Inclusion and democracy. Oxford: Oxford University Press, 2000. 